\title{
Glial Fibrillary Acidic Protein Expression in Postnatal Development of WAG/Rij Rat Retina
}

\author{
Lyalya Akhiyarovna Musina ${ }^{1}$, Samat Sagadatovich Baygildin ${ }^{2}$ and \\ Zukhra Rashidovna Khismatullina ${ }^{3}$ \\ Original \\ Article \\ 'Department of Morphology FSBI "Russian Eye and Plastic Surgery Center" of Health \\ Ministry of the Russian Federation, Ufa, Russian Federation \\ ${ }^{2}$ "Ufa research institute of occupational health and human ecology», Ufa, Russian Federation; \\ Postgraduate student at Biological faculty of "Bashkir state university», Ufa, Russian \\ Federation \\ ${ }^{3}$ Department of Physiology and General Biology, Faculty of Biology, "Bashkir State \\ University», Ufa, Russia
}

\begin{abstract}
Introduction: WAG/Rij rat is an experimental model of retinal degenerative diseases intensifying with age. Degeneration begins in the photoreceptor cells layer, followed by disappearance of photoreceptor cells, migration of the pigment epithelium and disorganization of remaining retinal layers. However, the age of onset of the degeneration is unknown. The destroyed neurons of retina are usually replaced by glial cells. A typical marker for several types of glial cells is the glial fibrillary acidic protein (GFAP).

Aim of the Work: The aim of the study is to determine postnatal changes of GFAP expression in retina of WAG/Rij rats.

Material and Methods: WAG/Rij rats of both sexes and different ages: 1, 10, 15, 20, 30, 60, 180, 360 postnatal days (P) ( $\mathrm{n}=3$ for each age) were taken. The immunohistochemical analysis of GFAP expression in the retina of WAG/Rij rats was performed and the expression area was measured.

Results: Expression of GFAP in the retina is detected from P1 to P20 as a brown staining in the internal limiting membrane or as a brown lines on the inner retina. On P30 the glial fibrillary acidic protein is already detected in significant quantities in almost all layers of the retina of the experimental rats. From P60 to P360 the expression of GFAP in the retina of the WAG/ Rij rats is more pronounced and increases in direct proportion with the age.

Conclusion: It was found that GFAP expression in the retina of WAG/Rij rats increases in direct proportion to the age. The increasing GFAP expression in the retina of the WAG/Rij rats starting from the 30th postnatal day indicates an intensification of destructive processes in retinal neurons with age and their replacement by Müller cells.
\end{abstract}

Received: 28 February 2020, Accepted: 31 March 2020

Key Words: GFAP protein, gliosis, muller cells, retinal degeneration, WAG/Rij rat.

Corresponding Author: Samat Sagadatovich Baygildin, $\mathrm{PhD}$, junior researcher at «Ufa research institute of occupational health and human ecology», Ufa, Russian Federation; Postgraduate student at Biological faculty of «Bashkir state university», Ufa, Russian Federation, Tel.: +7 (347)255-57-03, E-mail: baigildin.samat@yandex.ru

ISSN: $1110-0559$, Vol. 44, No.1

\section{INTRODUCTION}

Retinitis pigmentosa (RP) is a heterogeneous group of inherited diseases that cause degeneration of photoreceptors in the human retina ${ }^{[1]}$. It causes histological changes detected initially as shortening of the photoreceptor outer segments and loss of photoreceptor followed usually by alterations in the retinal pigment epithelium and retinal $\operatorname{glia}^{[1,2]}$.

In WAG/Rij rats Lai Y.L. et al. ${ }^{[3]}$ described retinal degeneration characterized by an early onset and a slowly progressive course. Degeneration begins in the photoreceptor cells, followed by their disappearance, migration of the pigment epithelium and disorganization of remaining retinal layers ${ }^{[3,4]}$. Lai Y.L. et al. (1975) and Lai Y.L. et al (1980) $)^{[3,4]}$ reported, that retinal degeneration in Waj/Rij rats resembles RP temporally and morphologically. In WAG/Rij rat, reared under homogenous lowintensity cyclic light exposure, the b-wave amplitude of electroretinogram decreased, and its implicit time increased in the older age groups significantly more than in Wistar rats ${ }^{[5]}$. Prolonged implicit time and decreased b-wave amplitude of electroretinogram were shown in most RP cases compared with that in normal eyes ${ }^{[6]}$.

WAG/Rij rats are more sensitive to light than SpragueDawley rats ${ }^{[7]}$. In WAG/Rij rats, following light exposure 
a greater degree of photoreceptor degeneration was also found compared with F344 rats ${ }^{[8]}$. It has been suggested that changes in WAG/Rij rats' retina were caused by light-induced retinal degeneration, rather than hereditary degeneration ${ }^{[9]}$.

The destroyed neurons in the nervous tissue are usually replaced by proliferating glial cells. In the retina, these are Müller cells. A typical marker for several types of glial cells in the nervous tissue is the glial fibrillary acidic protein (GFAP) which is also detected in the cytoplasm of Müller cells ${ }^{[10,11,12]}$.

It is of interest to determine the GFAP in the retina of experimental WAG/Rij rats in postnatal ontogenesis, since it is not known precisely at what particular age the destructive processes of retinal neurons start and how fast they develop. The process has never been thoroughly studied before. This aspect has an important theoretical and practical significance since using an experimental model helps develop the methods of treating retinal degenerative diseases. The aim of the study is to determine postnatal changes of GFAP expression in retina of WAG/Rij rats.

\section{MATERIALS AND METHODS}

\section{Animals}

WAG/Rij rats of both sexes and different ages: 1,10 , $15,20,30,60,180,360$ postnatal days $(\mathrm{P})(\mathrm{n}=3$ for each age) were taken. The rats were kept in the light for $14 \mathrm{~h}$ and in the darkness for $10 \mathrm{~h}$ (light intensity: 32-65 lux at cage level) with ad libitum access to food and water, were obtained from the Vivarium of Bashkir State University. All the procedures were approved and monitored by the ethics committee of Bashkir State University and followed the European Community Council Directive of September 22, $2010(2010 / 63 /$ EEC). The study was performed in accordance with the Rules of Work using Experimental Animals (Annex to the Order of the Ministry of Health no. 755 dated Aug. 12, 1977). The rats were deeply anesthetized with diethyl ether and decapitated. Both eyes were removed by enucleation and were fixed in $10 \%$ neutral buffered formalin for at least $48 \mathrm{~h}$.

\section{Tissue preparation and immunohistochemistry}

Formalin-fixed samples were embedded in paraffin after dehydration in ascending alcohol concentrations ending in xylol. Thin tissue sections $(5 \mu \mathrm{m})$ were prepared using rotary microtome (Leica RM 2145, Germany). Identification of a highly specific glial cell marker glial fibrillary acidic protein was performed using the immunohistochemical method, according to the manufacturer's protocol, using mouse monoclonal antibodies (catalog no.sc-33673; Santa Cruz Biotechnology, CA, USA) and the Leica Bond polymer refine detection kit (catalog no.DS9800; Novocastra, Germany). Sections of brain tissue expressing GFAP were used as a positive control. Negative controls were provided by omitting the primary antibody and replacing it with nonimmune serum. Staining was carried out on a Leica Bond Max autostainer (Leica, Germany).
Next, the samples were counterstained with hematoxylin and mounted in Bio Mount (Bio-Optica, Italy) ${ }^{[13]}$.

\section{Quantification analysis}

The area occupied by the brown colored GFAP in one visual field was measured at $\mathrm{x} 400$ magnification on an AXIO IMAGER-Z1 microscope (Carl Zeiss, Germany), using AxioVision Release 4.6. The area of the visual field on the histological specimens of the retina with the total magnification of the microscope amounted to $33,834.87$ $\pm 2,402.98 \mu \mathrm{m} 2$. In each group, measurements were performed in 30 fields of view in the mid-retinal regions ${ }^{[13]}$.

\section{Statistical Analysis}

Data analyses were performed using SPSS version 21 (IBM SPSS Statistics). The Gaussian distribution of data was verified using the Kolmogorov-Smirnov test. The values obtained were statistically analyzed using the one-way analysis of variance (ANOVA), followed by the Tukey's multiple comparison post-hoc test. The data were presented as mean $\pm \mathrm{SD}$. All the differences were considered significant when $P<0.05$.

\section{RESULTS}

The results of immunohistochemical studies of the retina of postnatal WAG/Rij rats showed that GFAP on P1 is visualized in small amounts as a brown staining only in the internal limiting membrane in the inner processes of Müller cells (Figure 1a). Immediately after birth, the inner nuclear and outer nuclear layers in the retina of rats do not separately differentiate, and therefore the outer plexiform layer between them can not be detected. The separation of the cell layers only occurs on P10, when a narrow outer nuclear layer appears between them. The expression of GFAP in the retina at that time is not enhanced and is detected in the same areas as after the birth. The same immunohistochemical pattern is observed on P15.

On P20 the expression of GFAP in the retina increases slightly. In some places, the protein is detected as single brown lines passing between the processes and perikarya of the ganglion neurons and penetrating into the inner plexiform layer up to the inner nuclear layer (Figure 1b). In some areas, the GFAP protein was seen in the form of thin lines and brown patches detected in the deeper layers of the retina. Therefore, on P30 the glial fibrillary acidic protein is already detected in significant quantities in almost all layers of the retina of the experimental rats (Figure 1c). From P60 to P360 the expression of GFAP in the retina of the WAG/Rij rats is more pronounced and increases in direct proportion with the age (Figure 1d).

To analyze the GFAP expression in the rat retina at different ages, the one-way Analysis of Variance (ANOVA) was used, followed by the Tukey's multiple comparison post-hoc test. The differences of mean values compared to P1 were statistically significant from the age of 30 days or more at $p<0.05$ (Figure 2). 

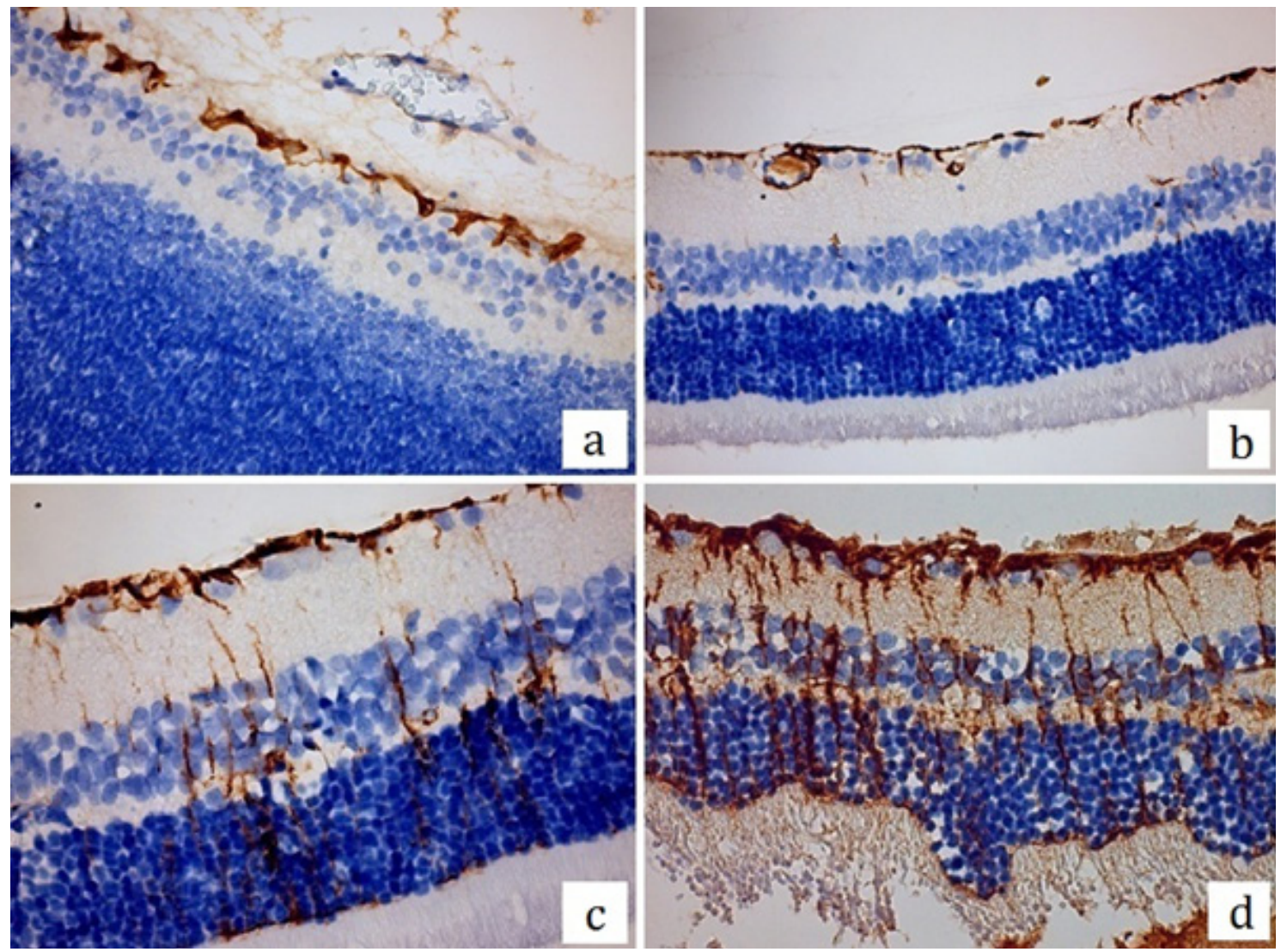

Fig. 1: Expression of GFAP (brown) in WAG/Rij rat retina on postnatal day 1(a), 20 (b), 30 (c), 360 (d). Indirect immunoperoxidase method with hematoxylin counterstain. Magnification 400x

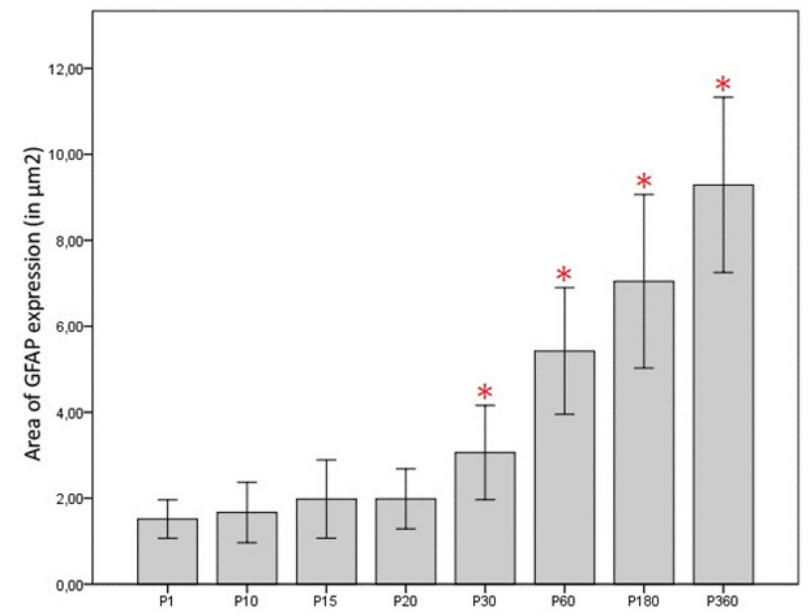

Fig 2: The area of the GFAP expression in WAG/Rij rats retina in postnatal development (in $\mu \mathrm{m} 2$ ). The values represent mean $\pm \mathrm{SD}, \mathrm{N}=3$ per group. Asterisk indicates significant difference compared with $\mathrm{P} 1$ at $p<0.05$

\section{DISCUSSION AND CONCLUSION}

The expression of the glial fibrillary acidic protein in a small amount in the inner processes of Müller cells in the region of the internal limiting membrane on the first day after the birth of rats is characteristic of the normal retina. This phenomenon had been discovered by a previous research in the retina of Wistar rats ${ }^{[14]}$. Immunocytochemically, the GFAP was insignificantly detected only in the region of the inner limiting membrane formed by the internal processes of Müller cells ${ }^{[14]}$.
In the nervous tissue, it is known that the destroyed neurons are replaced by Müller cells (gliosis). The excessive synthesis of the glial fibrillary acidic protein in the nervous tissue is a response to the destruction of neurons and plays a major role in the formation of a glial scar in the brain $^{[10,15,16,17]}$. The increased expression of GFAP is thought to help stabilize the newly formed terminal processes of Muller cells and provide resistance to mechanical stress ${ }^{[18]}$. In chronic pathological conditions, the hypertrophied end-feet processes of Muller cells help to fill the gaps left by dying photoreceptors and participate in the formation 
of "rings", which appear to prolong the survival of the remaining cone photoreceptors ${ }^{[19]}$. The hypertrophied processes are thought to prevent neovascularization and reduce monocyte infiltration by building a glial barrier at the outer edges of the neuroretina ${ }^{[20]}$.

A similar age-related increase in the GFAP immunoreactivity had been observed in $\mathrm{P} 23 \mathrm{H}-3$ (a proline to histidine substitution at codon 23 in the rhodopsin gene, line 3) rat, a transgenic model of Retinitis Pigmentosa ${ }^{[18]}$. In this model, the loss of photoreceptors triggers major changes in the number and morphology of glial cells affecting the inner retina. Rearing at 5 lux upregulate GFAP expression in Muller cells in both Sprague-Dawley and $\mathrm{P} 23 \mathrm{H}-3$ strains compared rearing at 40-60 lux. But the changes were more marked in the $\mathrm{P} 23 \mathrm{H}-3$ rats ${ }^{[21]}$. Increased expression of GFAP began in retina of $\mathrm{P} 23 \mathrm{H}-1$ rats at $\mathrm{P} 21^{[22]}$ and in RCS (Royal College of Surgeons) rats, other animal model of Retinitis Pigmentosa, at P30 ${ }^{[23]}$ or at $\mathrm{P} 45^{[22]}$

The role of glial cells in the reparative processes in case of the retinal damage is great ${ }^{[24,25,26,27,28]}$. It has been established that the radial glia of the rat retina reacts to the damage, just like astrocytes of the brain, by accumulating the GFAP, which is of great importance for fibrillogenesis $[15,12]$. The accumulation of this protein was observed in humans with the retinal reactive gliosis ${ }^{[10,17,29]}$.

As reported previously, we also found that the reaction of retinal pigment epithelial cells and Müller cells of the WAG/Rij rats retina to injury is ambiguous and is characterized by manifestations of both destructive and proliferative changes accompanied by changes in the degree of the retinal GFAP expression ${ }^{[14]}$. The proliferative activity of Müller cells results in the isolation of the abnormal foci from the normal tissues, which is a reflection of the body's adaptive reactions to injuries ${ }^{[11,12]}$.

As mentioned, the studies carried out have shown the degree of the GFAP expression in the retina of the WAG/ Rij rats at different ages. The amount of GFAP in the retina of rats increases in direct proportion to the age. The increasing expression of the protein in the retina of the WAG/Rij rats starting from the 30 th postnatal day indicates an increase of the destructive processes of retinal neurons with age and their replacement by Müller cells.

\section{ACKNOWLEDGMENTS}

This research did not receive any specific grant from funding agencies in the public, commercial, or not-forprofit sectors.

\section{CONFLICT OF INTERESTS}

There are no conflicts of interest.

\section{REFERENCES}

1. Milam AH, Li ZY, Fariss N: Histopathology of the human retina in retinitis pigmentosa. Prog Retin Eye Res. (1998) 17(2): 175-205.
2. Oh J, Kim SH, Kim YJ, Lee H, Cho JH, Cho YH, Kim CK, Lee TJ, Lee S, Park KH, Yu HG, Lee HJ, Jun SC, Kim JH: Detection of retinitis pigmentosa by differential interference contrast microscopy. PloS one. (2014) 9(5).

3. Lai YL, Jacoby RO, Jones AM, Papermaster DS: A new form of hereditary retinal degeneration in Wag/Rij rats. Invest Ophthalmol. (1975) 14(1): 62-67.

4. Lai YL, Jacoby RO, Jensen JT, Yao PC: Retinitis pigmentosa Animal model: hereditary retinal degeneration in Wag/Rij rats. Am J Pathol. (1980) 98(1): 281-284.

5. Cillino S, Guarneri R, Guarneri P, Pennica C, Chichi G, Piccoli F, Ponte F: Electroretinographic response in WAG/Rij rats after low-intensity cyclic light exposure. Ophthalmic Res. (1993) 25(3): 137-144.

6. Marmor MF: The electroretinogram in retinitis pigmentosa. Arch Ophthalmol (1979) 97(7): 1300-1304

7. O'Steen WK, Donnelly JE: Chronologic analysis of variations in retinal damage in two strains of rats after short-term illumination. Invest Ophthalmol Vis Sci. (1982) 22(2): 252-255.

8. LaVail MM, Gorrin GM, Repaci MA: Strain differences in sensitivity to light-induced photoreceptor degeneration in albino mice. Curr Eye Res. (1987) 6(6): 825-834.

9. LaVail MM, Papermaster DS, Bridges CD, Rapp LM, Gonzalez-Fernandez F, Hollyfield JG: Absence of an inherited retinal degeneration in the WAG-Rij rat. Exp Eye Res. (1987) 44(3): 465-469.

10. Hausmann R, Riess R, Fieguth A, Betz P: Immunohistochemical investigations on the course of astroglial GFAP expression following human brain injury. Int $\mathrm{J}$ Legal Med. (2000) 113(2): 70-75.

11. Bringmann A, Iandiev I, Pannicke $T$, Wurm A, Hollborn M, Wiedemann P, Osborne N, Reichenbach A: Cellular signaling and factors involved in Müller cell gliosis: neuroprotective and detrimental effects. Prog Retin Eye Res. (2009) 28(6): 423-451.

12. Devoldere J, Peynshaert K, De Smedt S, Remaut $\mathrm{K}$ : Müller cells as a target for retinal therap. Drug Discov Today. (2019) 24: 1483-1498.

13. Sarkisov DS and Petrov YuLM: Mikroskopicheskaya tekhnika: Rukovodstvo [Microscopic technique: Manual]. Meditsina, Moscow. (1996):125-153. 
14. Musina L, Khismatullina Z, Balkhieva L, Baigildin S, Vakhitova E: Characteristics of the radial gliocytes of experimental rats retina with pigment degeneration. Bulletin of OSU. (2014) 12: 226-228.

15. Türkmen N, Eren B, Fedakar R, Akgöz S, Comunoğlu N: Glial fibrillary acidic protein (GFAP) and CD34 expression in the human optic nerve and brain in methanol toxicity. Adv Ther. (2008) 25(2): 123-132.

16. Vázquez-Chona FR, Swan A, Ferrell WD, Jiang L, Baehr W, Chien WM, Fero M, Marc RE, Levine EM: Proliferative reactive gliosis is compatible with glial metabolic support and neuronal function. BMC Neurosci. (2011) 12(1): 98.

17. Ghosh F, Johansson K: Neuronal and glial alterations in complex long-term rhegmatogenous retinal detachment. Curr Eye Res. (2012) 37(8): 704-711.

18. Fernández-Sánchez L, Lax P, Campello L, Pinilla I, Cuenca N: Astrocytes and Müller cell alterations during retinal degeneration in a transgenic rat model of retinitis pigmentosa. Front Cell Neurosci. (2015) 9: 484.

19. Lee EJ, Ji Y, Zhu CL, Grzywacz NM: Role of Müller cells in cone mosaic rearrangement in a rat model of retinitis pigmentosa. Glia. (2011) 59(7): 1107-1117.

20. Nakazawa T, Takeda M, Lewis GP, et al: Attenuated glial reactions and photoreceptor degeneration after retinal detachment in mice deficient in glial fibrillary acidic protein and vimentin. Invest Ophthalmol Vis Sci. (2007) 48(6): 2760-2768.

21. Walsh N, van Driel D, Lee D, Stone J: Multiple vulnerability of photoreceptors to mesopic ambient light in the $\mathrm{P} 23 \mathrm{H}$ transgenic rat. Brain Res. (2004) 1013(2): 194-203.
22. Di Pierdomenico J, García-Ayuso D, Pinilla I, Cuenca N, Vidal-Sanz M, Agudo-Barriuso M, Villegas-Pérez MP: Early events in retinal degeneration caused by rhodopsin mutation or pigment epithelium malfunction: differences and similarities. Front Neuroanat. (2011) 11: 14.

23. Zhao $\mathrm{T}$, Li $\mathrm{Y}$, Weng $\mathrm{C}$, Yin $\mathrm{Z}$ : The changes of potassium currents in RCS rat Müller cell during retinal degeneration. Brain Res. (2012) 1427: 78-87.

24. Hippert C, Graca AB, Barber AC, West EL, Smith AJ, Ali RR, Pearson RA: Müller glia activation in response to inherited retinal degeneration is highly varied and disease-specific. PLoS ONE. (2015) 10(3).

25. Kaur C, Sivakumar V, Yong Z, Lu J, Foulds WS, Ling EA: Blood-retinal barrier disruption and ultrastructural changes in the hypoxic retina in adult rats: The beneficial effect of melatonin administration. J Pathol. (2007) 212(4): 429-439.

26. Sukhorukova EG, Korzhevskiı̌ DE, Kirik OV, Korzhevskaia VF: Detection of brain astrocytes by the immunohistochemical method after craniocerebral injury. Sud Med Ekspert. (2010) 53(1): 14-16.

27. Wang $\mathrm{X}$, Fan J, Zhang $\mathrm{M}, \mathrm{Ni} \mathrm{Y}, \mathrm{Xu}$ G: Upregulation of SOX9 in Glial (Müller) cells in retinal light damage of rats. Neurosci Lett. (2013) 556: 140-145.

28. Xue LP, Lu J, Cao Q, Hu S, Ding P, Ling EA: Müller glial cells express nestin coupled with glial fibrillary acidic protein in experimentally induced glaucoma in the rat retina. Neuroscience. (2006) 139(2): 723-732.

29. Paulus YM, Kaur K, Egbert PR, Blumenkranz MS, Moshfeghi DM: Human histopathology of PASCAL laser burns. Eye (Lond). (2013) 27(8): 995-996. 